\title{
IMPLICATIONS OF THE COPERNICAN PRINCIPLE FOR MY MASTERS THESIS
}

\author{
STEVAN A. SPRINGER
}

Department of Biological Sciences, Simon Fraser University,

Burnaby, British Columbia, Canada; V5A 1 S6.

E-mail: saspring@sfu.ca

\section{ABSTRACT}

Making only the assumption that you are an intelligent observer, an answer to the question: "So when will you be done your thesis anyway?" can be derived at the 95\% confidence level. Estimates for the duration of my thesis (17.4 days to 72.7 years) agree, within an order of magnitude, with my life expectancy.

\section{INTRODUCTION}

The first year of graduate school teaches us that it is a mistake to assume, without sufficient reason, that we occupy a privileged position in the University ${ }^{1}$. A casual survey of any communal graduate student office is enough to show that there are few window places, and many non-window places; the Universe is much the same. The Copernican Principle, the idea that our location is not spatially or temporally unique, has been used to estimate the expected lifetime of our species ${ }^{2}$ and has predicted, with remarkable accuracy, the existence ${ }^{3,4}$ and spectrum ${ }^{5}$ of cosmic background radiation. The knowledge that I am not, in any way, special and the assumption that you are a random intelligent observer will be used to estimate the probable future longevity of my Masters thesis.

\section{METHODS AND MATERIALS}

\section{Field Sampling}

Pages 315 to 319 were removed from the library's copy of Nature volume 363, creased, and incubated for 26 cycles of $19 \mathrm{~h}$ at $37^{\circ} \mathrm{C}, 5 \mathrm{~h}$ at $21^{\circ} \mathrm{C}$, in a Levi's $501 \mathrm{red}$ tab thermal cycler. Following thermal cycling, samples were washed once in $9944 / 100 \%$ pure sodium lauryl sulphate, rinsed in $\mathrm{ddH}_{2} \mathrm{O}$ and partially dried at $42^{\circ} \mathrm{C}$ for $\$ 1.25$ in a 1974 Maytag spinvac. Samples were removed from temporary storage, pressed flat, and lost in a stack of identically treated samples for archival storage.

\section{Statistical Analysis}

I am not a statistician; while my brain is theoretically capable of mathematics ${ }^{6}$ public schooling left me far too lazy to learn ${ }^{7}$ so I became a biologist. Please assume that all equations, any species of 
hieroglyphic punctuated by one of these $(\cong, \Sigma, \geq)$ or more commonly these $(\% @ \# !)$, have been plagiarized directly from Gott ${ }^{2}$. Often these characters will be made especially large in an attempt to draw your attention, or inflate their apparent importance; however, you need not pay much attention to the equations, as my computer has probably not printed them properly to begin with ${ }^{8}$.

\section{Wasting t Argument}

Suppose that the University forms intelligent undergraduate students at a uniform rate and that a proportion of these students become graduate students. A graduate student is an undergraduate student who has abandoned self confidence and the ability to reason abstractly and independently in favor of self imposed humiliation, colloquially referred to as a "thesis", and roughly $1.5 \times 10^{4}$ dollars per year. The amount of time a thesis has been observable in the past is directly related to a student's ability to avoid thinking, and dodge contact with a supervisor. Thesis duration provides an estimate of a student's ability to engage in diversionary activities in the past, and is also an indication of robustness to future supervisory pressure.

Assume that a thesis can only be observed between the times $t_{\text {suckered in }}$ and $t_{\text {defense }}$ and that $t_{\text {now }}$ is an observation taken at a random time within that interval. There is a $50 \%$ chance that the estimate $\mathrm{t}_{\text {future }}=($ $\left.t_{\text {defense }}-t_{\text {now }}\right)=t_{\text {past }}=\left(t_{\text {now }}-t_{\text {suckered in }}\right)$ will overestimate the time remaining in the thesis. For any random number $r=\left(t_{\text {now }}-t_{\text {suckered in }}\right) /\left(t_{\text {defense }}-t_{\text {suckered in }}\right)$ uniformly distributed between 0 and 1 there is a probability $\mathrm{P}=0.95$ that

$1 / 39 t_{\text {past }}<t_{\text {future }}<39 t_{\text {past }}(95 \%$ confidence level $)$

\section{RESULTS}

At the time of this writing I have been "working" on my Masters thesis for 680 days. Applying equation (1) predicts that, if writing this manuscript is not a prelude to mental breakdown or suicide, my thesis will last at least 17.4 days and not more than 26520 days $(\mathrm{P}=0.95)$. 


\section{DISCUSSION}

The notion that I am not special has been extended to show that my Masters degree is only somewhat

likely to be awarded posthumously.

\section{Implications for My Future Prospects}

The assumptions of equation (1) are not valid over extremely long or extremely short time intervals and I am, sadly, not able to estimate how long it will be before I have sex again or how long that event is expected to last.

\section{ACKNOWLEDGEMENTS}

I thank T. Chapman, S. Hoover, T. Hoover, R. Sargent, J. Sutton, J. Tyerman and members of the FABLab for shaping my opinion of graduate school.

\section{REFERENCES}

1. Robertson, J. Emerson, E. Gregory, N. Hatton, C. Kessisoglou, S. Hallam, A. and Linehan, C. 2001. Social networks of people with mental retardation in residential settings. Mental Retardation 39:201-214

2. Gott III, R.J. 1993. Implications of the Copernican Principle for our future prospects. Nature 363:315-319

3. Alpher and Herman 1948. Evolution of the Universe. Nature 162:774-775

4. Gamow, G. 1948. The origin of elements and separation of galaxies. Phys. Rev. 74:505-506.

5. Mather, J.C. Cheng, E.S. Eplee, R.E. 1990. A preliminary measurement of the cosmic microwave background spectrum by the cosmic background explorer satellite. Astrophys. J. 354:L37-L40

6. Bottge, B.A. 2001. Reconceptualizing mathematics problem solving for low-achieving students. Remedial and Special Education 22:102-112

7. Robbins, T. and Covan, F.L. 1993. Awaken the Giant Within: How to Take Immediate Control of Your Mental, Emotional, Physical \& Financial Destiny. Fireside, New York

8. When faced with an equation that actually needs to be displayed properly, I find it best to treat it as you would an envelope and spend all afternoon trying to get it to print properly before giving up and writing it by hand. 